\title{
THE IMPACT OF THE CAUSE RELATED PRODUCTS PROMOTIONAL CAMPAIGNS ON CONSUMER BEHAVIOR
}

\author{
Oana PRICOPOAIA ${ }^{a^{*}}$, Nicoleta CRISTACHE ${ }^{b}$,Adriana MATEI ${ }^{c}$, Cosmin MATIȘ ${ }^{d}$, \\ Teodora Nicoleta LAZÄR (PLEȘA) \\ ${ }^{a}$ Transilvania University of Brașov, România \\ ${ }^{b, c}$ Dunărea de Jos Uiversity of Galati, România \\ ${ }^{d}$ Babeș-Bolyai University, Cluj-Napoca, Romania \\ ${ }^{e}$ Universitatea Valahia din Târgoviște, România
}

DOI: $10.24818 / \mathrm{IMC} / 2020 / 02.10$

\begin{abstract}
Consumer involvement in promotional campaigns for different products depends on the degree to which the consumer considers the advertisements to be interesting, worth listening to and supporting a real cause. The more suggestive the ads, the more dramatic and intense experience they offer in the mind of the consumer. The emotional intensity determines the way the emotions transmitted by an advertisement are experienced. The promotion of a cause related product is based on raising the awareness of the target audience through the supported cause, in this case counting the emotional flow and the way of integrating emotions in the ads. The emotions represented in the advertisement can have a static or dynamic flow. Consumers accept more easily companies that prove that they have a civic spirit and fight for a cause. By purchasing a product from a company that promotes itself through Cause Related Marketing, the consumer will receive both the chosen product and the symbolic value that goes beyond the promised quality associated with the product to social responsibility.
\end{abstract}

KEYWORDS: promotion, product related to a cause, emotion, consumer behavior, marketing, social responsibility.

\section{INTRODUCTION}

Cause Related Marketing is a tool widely used by companies in the market in which they operate. There are many benefits for companies that integrate cause related marketing into their promotional campaigns, including: attracting new customers, increasing sales of products or services, creating a favorable image in the market in which the brand operates and last but not least engages in raising funds for a social cause. More and more companies are studying the concept of social responsibility and are rapidly moving from the process of conceptual identification and definition to implementation (Leon Schiffman et al., 2013).

Cause Related Marketing (CRM) is part of the Corporate Social Responsibility (CSR) initiative. CRM is a program through which a company shows its desire and voluntarily engages in a concrete action to donate a sum of money based on the sales it makes over a period of time, established from the beginning in favor of a cause. The CRM campaign is valid for a well-defined period, refers to a specific product, is carried out to benefit a non-governmental organization, a natural or legal person or a partner who has the right to manage the money for the promoted cause (Michael R. Solomon, 2017) Business in the Community (BITC), 2004, defined Cause Related Marketing as a commercial

\footnotetext{
${ }^{*}$ Corresponding author. E-mail address: oana.pricopoaia@unitbv.ro
} 
activity through which companies, non-governmental organizations and social causes form a partnership that aims to promote an image, product or service in the common interest.

Cause Related Marketing involves two main participants: the company that wants to support a cause and the cause of the person or non-governmental organization referred to (Mothersbaugh \& Hawkins, 2015). The relationship between the two participants is based on a commercial commitment that benefits both the company by increasing sales of the product that is related to the social cause leads to the creation of a favorable image on the market, and the cause distribution of a percentage of sales to the person who has the commitment and ability to use the money. However, without consumer participation, campaigns related to a cause cannot guarantee success (Kumar, 2015).

\section{EMOTION IN ADVERTISING}

Emotions have a special role in advertising, if the advertisement successfully introduces the appropriate emotions to sensitize the consumer, stronger links can be created between the company and the customer (Botha et al., 2016). Emotional connections can increase the level of preference for a brand, help strengthen the company's image in the market and increase product sales.

The emotional state puts some pressure on the consumer's mind and influences him in the purchasing decision. Positive or negative emotions can be used in awareness-raising advertisements (Emerald Group Publishing Limited, 2015).

The emotional content of the advertisement leads to the exercise of emotional reactions, most of the ads based on public awareness focus on: humor, suspense, care, love, optimism, humanitarian causes, philanthropy (Acevedo, 2018). Often these emotions, being positive, influence the decision of purchasing a product and create a strong connection between the customer and the company. By using emotions in promotional campaigns, three aspects can be achieved: determining a positive attitude among the customer towards the promoted product, unique benefit obtained from using that product and increasing the efficiency of advertising (Campbell, 2011).

An emotion can be the point of persuasion in an advertisement in the consumer's determination to buy the product if several aspects are taken into consideration:

- the message sent;

- the way the message is transmitted;

- a person, a character or object associated with the advertisement (a baby, a celebrity, a model worth following, an object - a teddy bear)

The cognitive activity determined by the emotional states in an advertisement occurs quickly, generating a strong behavior, and the individual who comes in contact with the product is willing to purchase it without too much hesitation (Stieler, 2016). An advertisement does not train people, it is known that emotions are pre-existing, and consumers only develop emotional experiences that are being emphasized (Iviane Ramos et al., 2019).

Campaigns to promote products related to a cause considered effective are those that aim to create a propensity to react in a desired way by the company or brand when a consumer is in a clearly emotional state (Sastry, 2019).

Campaigns to promote a product related to a cause are based on emotions, and they should be used depending on how the consumer forms his attitude towards that product after making an association between the promoted emotion and the brand communication element (Lee \& Kotler, 2019). In the case of advertisements promoting Cause Related Products, there are two situations: acceptance or rejection.

Acceptance is manifested when there is public awareness, and rejection is often manifested when the human psyche cannot tolerate a higher price or there is no appreciation for the promoted product or is not sensitized by such cases (Maison, 2019). Advertisements that present an emotion emphasize the emotional state as a benefit that results from using that product. 
Thus, the aim is to create a behavioral predisposition to be interested in buying and using it (Szmigin \& Piacentini, 2018). Emotion must be triggered not only at seeing that product, but also at the time of use and after use.

Thus, the use of emotions in promoting Cause Related Products follows the steps:

- initial emotional context (product promotion using awareness effects);

- behavioral propensity (the emotion that is emphasized);

- the final reward (the benefit is considered to provoke an emotion).

The consumer's emotional experience with the product discussed results in a triggering emotion benefit (final reward). The emotional involvement of consumers is observed when paying attention to the characters or objects in the advertisement, the way the message and emotions are transmitted (Krishna, Taylor \& Francis, 2009).

The more consumers are attracted to the advertisements in which the emotion is promoted, the more they react more strongly to the display of advertisements, the more likely they are to recall their message and elements. (Belk \& Llamas, 2013).

There is no clear process established by strict rules to promote known emotions that cause the public to be aware, but the perfect association must be identified between the message that is transmitted, what emotion is promoted, what is the product related to a cause, what character or object it is used and last but not least what is the way of transmission. All these aspects integrated in a strong campaign increase the success of the advertisement (Lewis, 2018).

\section{MARKETING AND AWARENESS}

Many managers still believe that the target audience makes decisions in an argumentative, rational and linear way, and the reflection on the individual values of the characteristics of an object is purely rational (Allan J Kimmel, 2018). But people's emotions are closely related to the rational process of choosing a product, processing emotions and supporting reasoning, although it works separately, influences consumer behavior at the same time and very strongly (Kirchler \& Hoelzl, 2017).

The decision-making process is influenced and depends on the simultaneous functioning of reason and emotions. Some marketers believe that emotions can be easily verified and described by consumers, but by definition they are unconscious (Foxall, 2015). In order to be triggered in a positive way by purchasing products, companies use special techniques based on reminding, awareness and increasing the self-esteem.

Advertising campaigns can be evaluated through surveys, for example, consumers are asked if they liked the presentation, what details attracted their attention, what they would change and what would be the element that had the greatest impact on memorizing the advertisement (Kartikeya Kompella, 2018). The messages that consumers receive from advertisements may be different because they have different thinking, and extracting details from the proposed campaigns contributes to creating their own story about the message (Frank Kardes, Maria Cronley, Thomas Cline, 2014).

Behind a marketing message is a story created in the mind of the consumer that we will not decipher if we do not find out what and how thinks (creatively or rationally) the audience we address (Pligt \& Vliek, 2016).

Marketers cannot accurately anticipate customers' reaction to advertised products if their thoughts and feelings are not known (Mazurek \& Tkaczyk, 2016). The target audience must be as well determined as possible so that the marketing action reaches the determined groups as soon as possible. Marketing controls the process of focusing on the customer by identifying the obvious and latent needs of potential customers (Bischoff, 2012). Cause Related Marketing involves two main participants: the company that wants to support a cause and the cause it refers to that belongs to a non-governmental organization (Adkins, 2016). The relationship between the two participants is based on a commercial commitment that benefits both the company by increasing sales of the 
product that is related to the social cause leads to creating a favorable image on the market, and the cause distribution of a percentage of sales to the company has the commitment and ability to use money (Siebert, 2014). However, without the participation of the consumer, campaigns related to a cause cannot guarantee success. Thus, in this sense, consumers must understand that they are active participants in a certain social cause, buying the promoted product can support that cause (Basil et al., 2019). Marketing related to a cause includes the donation that consumers make for a social cause, a donation that is made by purchasing the product or service that is the subject of the claimed cause. This social responsibility activity is part of a company's marketing department (Cialdini, 2016). The consumer participates in the donation activity and has the satisfaction of having done a good deed by supporting the cause, being at the same time a business partner in the process contributing indirectly (Schiffman \& Kanuk, 2014). The connection between buying a good and supporting a cause through the funds obtained from the sale is the purest form of marketing related to a cause. This whole process involves a non-governmental organization whose cause is supported by promoting a product that will get a percentage of the profits from those sales (Lee \& Kotler, 2019). The company is committed to supporting causes, and through this activity works with a nongovernmental organization, and the gain will be on both sides: for the company is an effective way to increase brand awareness, create brand value and improve financial performance, and for the non-governmental association contributing to the support of the cause by raising money or objects (Muthu, 2018). Companies that support a cause are more likely to gain sympathy and trust among the public, because activities related to a social cause raise consumer awareness, loyalty and increase the company's reputation. CRM helps marketers stay connected with the target audience, know their status and desires, because in promoting the company's activity they use more sensitive, realistic, concrete tools which are relevant to society. The benefits of adopting case-related marketing are:

- increase the sale of some products or services that are the object of the CRM campaign;

- attracting new customers through awareness;

- identifying a new category of customers who are passionate about social causes;

- improving the image on the market;

- increasing brand awareness;

- building a favorable image among the target audience;

- and the most important benefit that is the object of this type of marketing - raising the necessary funds for a social cause.

\section{QUALITATIVE RESEARCH ON THE IMPACT OF CAUSE RELATED PRODUCTS PROMOTION ON CONSUMER BEHAVIOR}

\subsection{Research methodology}

Two hypotheses have been created that will be verified using a case study.

H1: In a procurement process involving marketing related to a cause, respondents will tend to buy the product that supports a social cause.

H2: Relevant emotions felt by respondents will be specific to the collectivist culture (focused on others).

To examine the hypotheses developed, we adapted the scenario used by Kim Jhonson in "The Impact of Moral Emotions on Cause Related Marketing Campaigns: A Cross-Cultural Examination" in which respondents are asked to choose one of two identical products, with the difference that by purchasing one of them, it is supported to combat a social problem, the product in question being $10 \%$ more expensive.

To verify the realism of the scenario and the relevance of the chosen product in the created context (a T-shirt), a pilot test was launched to 10 students raised in the US, representing individualistic culture, and to 10 students from Korea, collectives. They were asked to rate the two dimensions on 
a scale of 1 to 7 . Results showed that the T-shirt is a relevant product in that context $(\mathrm{M}=6.0)$, and the scenario realistic $(\mathrm{M}=5.9)$.

The data collected following the online questionnaire represented the answers of 208 people, aged between 18 and 42 years $(M=21.75)$, most of them being Romanian students, graduates of high school $(62.5 \%)$. Taking into account the limitations in space and time, the case study tool was distributed to potential respondents in the form of an online questionnaire consisting of 75 variables, divided into three sections. In the first part of the questionnaire, the respondents filled in demographic data such as: sex, age, background, level of education, monthly income and whether they have brothers/sisters. In the second section, they completed the scale for measuring Singelis' independent and interdependent self-perception (1994) and the scale developed in 2007 by researchers at the University of Auckland, New Zealand (AICS) for measuring individualistic and collectivistic orientation.

The next step was to introduce the scenario to the subjects, formulated so as to induce in them the real experience of a moral decision in a buying situation. They were asked to read it, and at the end to close their eyes and choose between the two articles. After making the choice, to evaluate the intensity of the following emotions: guilt, empathy, gratitude, frustration, pride and embarrassment. Scenario offered to the subjects: You are in a mall where a variety of fashion products are offered for sale. The products offered include: clothing, handbags or accessories. Imagine you are shopping here. While shopping, you find two t-shirts that you like equally. The first $t$-shirt is your favorite style and has a color you like. The T-shirt is also in your favorite style and color, but it has a label stating that if you buy it, a percentage of the profit will go to the Global Diabetes Foundation to fight obesity. The price of the second T-shirt is 10\% higher than the price of the first T-shirt. You can choose only one product. Before you make your choice, close your eyes.

In the last section, the participants evaluated on a scale from 1 to 7 (where $1=$ total disagreement and $7=$ total agreement) 21 items for measuring the purchase intention, translated from English into Romanian and adapted to the situation presented above.

\subsection{Analysis of the results}

After collecting the data set, the main consideration in choosing and establishing the final data was the age of the respondents. Thus, we removed from the initial data set (208 participants) all responses that came from people over the age of 25, including the final data set containing a total of 184 responses, given by people between $18-24$ years $(M=19.7)$ The majority of subjects were female (71.6\%), supported by a research study conducted in Australia, which showed that women are inclined to help a CRM campaign more than men, the remaining $28.4 \%$ being represented by the male part. In fact, $57.2 \%$ come from urban areas, with a monthly income between $0-1400 \mathrm{RON}$ $(55.8 \%)$, and the last level of study graduated by the majority is high school $(62.5 \%)$, followed by those who have a University degree $(29.8 \%)$. Please note that this percentage reflects values corresponding to the initial data set.

In the first phase, the subjects completed items for socio-demographic data, previous studies showing that demographic variables such as gender, age or income, can influence the conscious choices of the consumer.

In order to examine cultural self-perception, in the first section, two scales were merged in order to verify the integrity of the answers obtained that could be affected by the complexity and length of the questionnaire, this way some items were resumed and slightly modified, as follows: 'I will sacrifice my own interests for the benefit of the group' - Singelis Scale (1994) is found as: 'I sacrifice my own interests for the benefit of the group'.

In the Auckland Scale for Individualism and Collectivism (2007), the latter being developed on the basis of the first scale. Subjects rated the items' answers using a 7-point Likert scale, where $1=$ total disagreement and $7=$ total agreement. An example of an item that measures the individualistic side is variable 17: 'I define myself as a competitive person', and among the factors associated with collectivism we find item number 6: 'I hate to oppose others in my group'. 
In terms of measuring moral emotions and observing the intensity with which they were felt, we selected empathy, guilt, and gratitude as strong examples of representative emotions for collectivists that result and are triggered by sensitivity and interaction with external stimuli. In contrast, frustration, pride and embarrassment were used as significant to the individualistic orientation, the stimuli triggered at the intrinsic level being those that moderate their appearance.

To indicate the intensity with which they experienced the above emotions, respondents rated them on a 5-dimensional scale as follows: "not at all"; "a little bit"; "enough"; "a lot" and "very much". The last measurement was that of the purchase intention which was verified using Gill's scale, modified to fit the scenario in question. Respondents were asked to rate on a Likert scale with 7 points, where $1=$ total disagreement and $7=$ total agreement, variables on the given situation.

The first step in creating the model was to encode non-numeric variables and create latent variables. Thus, the initial model brought together a dependent variable: "Emotions", and 12 independent variables, under whose umbrella were specific and determining items as follows: "Scenario"; "Buying Intention"; "Harmony"; "Advice" "Responsibility"; "Uniqueness"; "Competitiveness"; "Age"; "Gender"; "Environment"; "Studies"; "Siblings".

After checking the correlation between the latent variables and the coefficients that defined them, we eliminated those that had a value of less than 0.7 , thus increasing the reliability of the remaining ones.

Therefore, the final model reflects the following latent variables and their indicators as follows: the dependent variable: "Emotion" ("em1"; "em2") and the independent variables: "Scenario" ("scen"); "Harmony" (“q5"; "q6”); "Uniqueness" ( "Q21", "Q22"); “Gender" ("var1”); "BI” (“bi111”; "bi115"); "Age" ("var2"), of which 2 are also moderators: "Uniqueness" for the correlation between "Harmony", "Scenario" and the dependent variable, and "Age" for the correlation between "BI" and "Emotions".

The internal confidence of the items for all measurements in the model was calculated using the fidelity coefficient, Cronbach's Alpha of the variables Uniqueness (0.855), Harmony (0.630), Scenario (1,000), Age (1,000), BI (0.708), Gender (1,000) and Emotions (0.841), Uniqueness * Harmony (0.659), Uniqueness * Scenario (0.841) and Age * BI (0.822). Because the minimum value of this coefficient is considered acceptable if it is at least 0.70 (but there are authors who accept 0.60 in the case of exploratory studies) we can therefore admit that we have an adequate internal consistency of the scale.

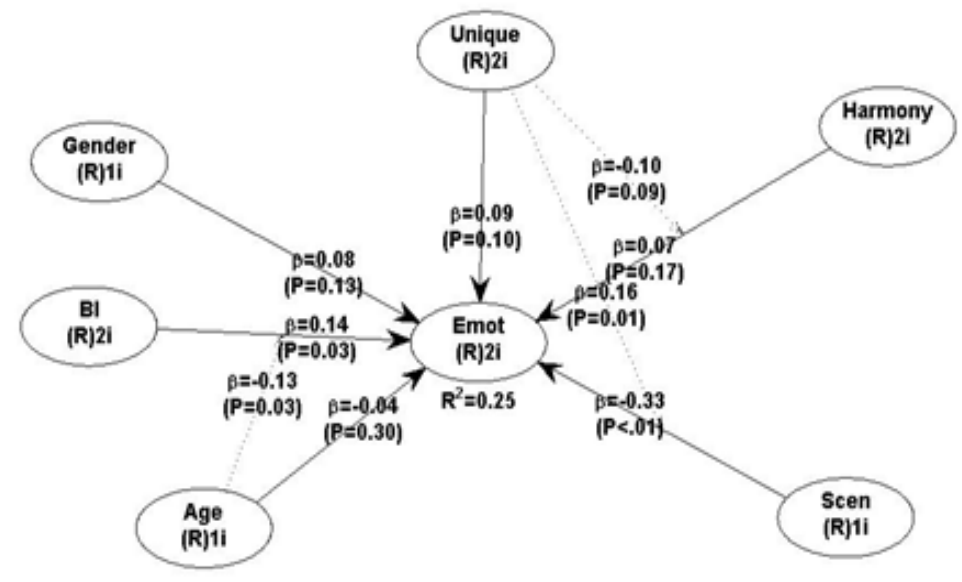

Figure 1. Final statistical model

Source: authors processing

Starting from the hypotheses presented in the first part, we can appreciate that the first hypothesis, H1: In a buying situation involving marketing related to a cause, Romanians will tend to purchase the product that supports a social cause, is supported by analyzing the answers, thus, $68.3 \%$ of the respondents chose the second t-shirt, the one that was related to a social cause. 
Regarding the second hypothesis: $\mathrm{H} 2$ : The relevant emotions felt by the respondents will be specific to the collectivist culture (focused on others.), We specify that it is statistically supported, because the significant emotions for our final model were guilt and embarrassment, both have loads of 0.929 , these representing emotions from the category of those specific to the collectivistic individual.

After eliminating all insignificant latent variables, we can see that the explanatory power of the model is $25 \%(\mathrm{R} 2=0.25)$, from which we deduce that the emotions felt after the choice made, guilt and embarrassment, are moderated by $25 \%$ by regressor variables (scenario, age, purchase intention, harmony, gender, uniqueness). The coefficients for the variables are found in Table 1 , as follows: Scenario $(\beta=-0.329)$, Uniqueness $(\beta=0.92)$, Harmony $(\beta=0.069)$, BI $(\beta=0.141)$, Gender $(\beta=0.082)$, Age $(\beta=-0.037)$, Age * BI $(\beta=-0.134)$, Uniqueness * Harmony $(\beta=-0.095)$, Uniqueness * Scenario $(\beta=0.158)$.

Considering these, we can deduce that the scenario influences the emotions of guilt and embarrassment, specifically collectivistic ( $p$ value $<0.001$ ).

Interaction between age and purchase intention plays a significant role on respondents' emotions ( $p$ $<0.5$ ), and the desire to be unique moderates the connection between the created scenario and the emotions felt $(p<0.5)$, which tells us that although the scenario is one that presents a context in which the collectivistic side can be accentuated, the fact that uniqueness is a factor influencing the connection between them denotes that the decision taken may be due to the desire to assert the unique self (individualistic).

Regarding the purchasing power $(\mathrm{BI}=0.025, \mathrm{p}<0.5)$, according to the results, it appears that its influence on the dependent variable is statistically significant. The rest of the interactions between the variables proved to be insignificant.

In the third column of Table 1, the values of the Cohen coefficient (Size Effect) are presented. All values are $<0.20$, which demonstrates that the impact of independent variables on the dependent variable is not relevant, as they are insignificant at the macroeconomic level. Consequently, future tests may resume the structure of this study on a larger number of respondents.

Table 1. Path coefficients, p-value and Size Effect.

\begin{tabular}{|l|c|c|}
\hline Variables & Emotions & Size Effect \\
\hline Scenario & $\begin{array}{c}-0.329^{* * *} \\
(<0.001)\end{array}$ & 0.0128 \\
\hline Uniqueness & $\begin{array}{c}0.92 \\
(0.103)\end{array}$ & 0.012 \\
\hline Harmony & $\begin{array}{c}0.069 \\
(0.171)\end{array}$ & 0.010 \\
\hline BI & $\begin{array}{c}0.141^{*} \\
(0.025)\end{array}$ & 0.024 \\
\hline Gender & $\begin{array}{c}0.082 \\
(0.129)\end{array}$ & 0.004 \\
\hline Age & $\begin{array}{c}-0.037 \\
(0.304)\end{array}$ & 0.003 \\
\hline Age*BI & $\begin{array}{c}-0.134^{*} \\
(0.032)\end{array}$ & 0.017 \\
\hline Uniqueness*Harmony & $\begin{array}{c}-0.095 \\
(0.095)\end{array}$ & 0.008 \\
\hline Uniqueness*Scenario & $\begin{array}{c}0.158^{*} \\
(0.014)\end{array}$ & 0.052 \\
\hline
\end{tabular}

Source: authors processing

\section{CONCLUSIONS}

The effects of social responsibility actions can be analyzed and interpreted both among companies and consumers. Among the companies, the employees are motivated to carry out environmentally 
friendly activities, to volunteer, to support a cause and to fight with a unitary ensemble to achieve success over a cause. Among consumers Cause Related Marketing has a direct impact on sales force performance, with much emphasis on how the company focuses on such campaigns targeting a group of stakeholders (consumers), but also how it mediates the relationships and reactions of the sales force involved in such campaigns.

Throughout life, people acquire certain beliefs and form attitudes towards certain products, services, actions developed by the company, all these aspects influencing their buying behavior. The attitude of consumers is different in terms of food, sports, clothing, music or other social issues, but the company must find the common factor to convince the customer to buy a product. The process of bringing the customer closer to the company that promotes a product, object of the campaign related to a cause goes through the stages: awareness-testing-repetition.

The seemingly neutral product to the consumer if he tells a story or is the subject of a humanitarian activity or a philanthropic action makes the customer aware that actively participates in the improvement of a situation or in the action of doing good. Accepting a higher price is easier if the consumer perceives that higher price difference if they understand that they are supporting a humanitarian cause.

The present paper aimed to verify the applicability of studies conducted in the field of consumer behavior and Cause Related Marketing, in the case of Romania considering two directions: decision and cultural orientation; emotions and connection with cultural orientation.

Although the two initial hypotheses were statistically supported, we must analyze the results taking into account the limitations brought by the fact that the sample used is unrepresentative for the Romanian population. Emotions directed towards external stimuli (specific to the interdependent self) proved to be significant for our model, but at the same time, uniqueness (indicator of individualistic orientation) was a significant moderator between scenario and emotions, which indicates that although Romania's population is considered being a collectivistic one, this does not completely eliminate the individualistic side and the fact that generations are constantly changing.

On the other hand, the intention to buy was significantly related to emotions, which indicates how emotions can moderate our decision to buy certain products, but also the reason behind the decision. Inevitably, there are limitations to this study. A first limitation in terms of the veracity of the results is given by the way the study was distributed to respondents, the online environment is not a safe one in which the sample can be created so as to lead to safe and credible results, and the fact that the majority of the participants were young people between the ages of 18 and 24 which represents a limitation, as individuals can change their values and level of perception at different stages of life.

Also, the complexity and length of the questionnaire can create a state of fatigue or boredom, and therefore the answers do not really reflect their real opinion. In fact, the emotions studied were imagined by the respondents, and between the really felt emotions and the imagined ones there is a difference in perception.

On the other hand, future studies may transpose the scenario used in this paper, in real life, to a larger sample. Moreover, future studies can compare the buyer's attitude towards a product that supports a cause, when it reflects a problem of national interest and the role of its awareness in a collectivist versus individualistic culture.

\section{REFERENCES}

Acevedo, C. (2018). Consumer Behaviour and Advertising Management, Editor Scientific eResources.

Adkins, S. (2016). Cause Related Marketing, Editor Routledge.

Basil, D. Z., Diaz-Meneses, G. \& Basil, M. D. (2019). Social Marketing in Action: Cases from Around the World, Editor Springer.

Belk, R. W. \& Llamas, R. (2013). The Routledge Companion to Digital Consumption, Editor Routledge. 
Bischoff, A. L. (2012). Cause Related Marketing: Fit as success factor in CRM, Editor GRIN Verlag.

Botha, E., du Toit, D. H., Erasmus, A. C., Maree, \& Mugobo, T. V., (2016). Consumer Behaviour: Understanding Consumer Psychology and Marketing, Editor Oxford University Press.

Campbell, C. L. (2011). The Customer is NOT Always Right? Marketing Orientations in a Dynamic Business World: Proceedings of the 2011 World Marketing Congress, Editor Springer.

Cialdini, R. B. (2016). Psihologia manipulării, Editor Elefant Online.

De Luna, I. R., Fitó-Bertran, A., Lladós-Masllorens, J. \& Liébana-Cabanillas, F., (2019). Sharing Economy and the Impact of Collaborative Consumption, Editor IGI Global.

Dr. Sastry, V. V. L. N. (2019). Consumer Behavior in Digital Age, Editor Idea Publishing

Emerald Group Publishing Limited. ( 2015). A Focus on Consumer Behaviours and Experiences in an Online Shopping Environment, Editor Emerald Group Publishing.

Foxall, G. R. (2015). The Routledge Companion to Consumer Behavior Analysis, Editor Routledge.

Joop van der Pligt \& Vliek, M. (2016). The Psychology of Influence: Theory, research and practice, Editor Routledge.

Kardes, F., Cronley, M. \& Cline, T. (2014). Consumer Behavior, Editor Cengage Learning.

Kimmel, A. J. (2018). Psychological Foundations of Marketing: The Keys to Consumer Behavior, Editor Routledge.

Kirchler, E. \& Hoelzl, E. (2017). Economic Psychology: An Introduction, Editor Cambridge University Press.

Krishna, A., Taylor \& Francis Group, (2009) - Sensory Marketing: Research on the Sensuality of Products. Univesity of Michigan

Kumar, D. (2015). Consumer Behaviour: Includes Online Buying Trends, Editor Oxford University Press.

Kompella, K. (2018). Marketing Wisdom, Editor Springer.

Lee, N. R. \& Kotler, P. (2019). Social marketing: behavior change for social good, Editor SAGE Publications.

Lee, N. R. \& Kotler, P. (2019) - Social Marketing: Behavior Change for Social Good, Editor SAGE Publications.

Lewis, A. (2018). The Cambridge Handbook of Psychology and Economic Behaviour, Editor Cambridge University Press.

Maison, D. (2019). The Psychology of Financial Consumer Behavior, Editor Springer.

Mazurek, G. \& Tkaczyk, J. (2016). The impact of the digital world on management and marketing, Editor Poltext.

Mothersbaugh, D. L. \& Hawkins, D. I. (2015). Consumer Behavior: Building Marketing Strategy, Editor McGraw-Hill Education.

Muthu, S. S. (2018). Consumer Behaviour and Sustainable Fashion Consumption, Editor Springer.

Schiffman, L., O'Cass, A., Paladino, A. \& Carlson, J. (2013). Consumer Behaviour, Editor Pearson Higher Education AU.

Schiffman, L. \& Kanuk, L. (2014). Consumer Behavior, Global Edition, Editor Pearson Education Limited.

Siebert, S. (2014). Cause Related Marketing: A Substitute for Direct Donations?, Editor Anchor Academic Publishing.

Solomon, M. R. (2017). Consumer Behavior: Buying, Having, and Being, Editor Pearson.

Stieler, M. (2016). Creating Marketing Magic and Innovative Future Marketing Trends: Proceedings of the 2016 Academy of Marketing Science (AMS) Annual Conference, Editor Springer.

Szmigin, I. \& Piacentini, M. (2018). Consumer Behaviour, Editor Oxford University Press. 